NBER WORKING PAPER SERIES

MORTALITY CONTINGENT CLAIMS, HEALTH CARE, AND SOCIAL INSURANCE

Tomas Philipson

Gary S. Becker

Working Paper 5760

NATIONAL BUREAU OF ECONOMIC RESEARCH 1050 Massachusetts Avenue

Cambridge, MA 02138

September 1996

We are thankful to Michael Boozer, David Bradford, Paul Gertler, James Heckman, Magnus Johannesson, Casey Mulligan, Sherwin Rosen, Jose Scheinkman, as well as seminar participants at the University of Chicago, NBER Summer Institute on Social Insurance, the 7th Annual Health Economics Conference at Boston University, the Stockholm School of Economics, and the Western Economic Association Meetings for comments. John Cawley and Tom Lawless provided valuable research assistance. Financial support for this project was provided by the John M. Olin Foundation, to which both authors are thankful. This paper is part of NBER's research program in Health Care. Any opinions expressed are those of the authors and not those of the National Bureau of Economic Research.

(C) 1996 by Tomas Philipson and Gary S. Becker. All rights reserved. Short sections of text, not to exceed two paragraphs, may be quoted without explicit permission provided that full credit, including $\mathbb{C}$ notice, is given to the source. 


\title{
MORTALITY CONTINGENT CLAIMS, HEALTH CARE, AND SOCIAL INSURANCE
}

\begin{abstract}
This paper analyzes the savings and health care impacts of mortality contingent claims, defined here as income measures, such as annuities and life-insurance, under which earned income is contingent on the length of one's life. The postwar increase in mandatory annuity and lifeinsurance programs, as well as the rapid increase in life-expectancy, motivates a better understanding of the effects that mortality contingent claims have on resources devoted to life-extension. We analyze the incentives that such claims imply for life-extension when resources may affect mortality endogenously and argue that these incentives dramatically alter the standard conclusions obtained when mortality is treated exogenously.
\end{abstract}

Tomas Philipson

Department of Economics

University of Chicago

1126 East 59th Street

Chicago, IL 60637

and NBER

toma1@cicero.spc.uchicago.edu
Gary S. Becker

Department of Economics University of Chicago 1126 East 59th Street

Chicago, IL 60637 


\section{Introduction}

The number of countries that have old age or survivor income programs provided through the public sector has increased by almost five times since 1940 -from 33 to $155^{1}$ Although the financing of these programs varies widely across countries, the benefits are paid out almost exclusively in terms of annuities and they often cover more than 90 percent of the labor force ${ }^{2}$. Furthermore, private pensions add to the degree of annuitization of most elderly populations. Public annuity programs are large, both in terms of levels and growth: in OECD countries they constitute about one-tenth of GDP, make up more than three-quarters of all social insurance in developed countries, and have contributed to a quarter of the growth in total public expenditures since $1960 .{ }^{3}$ As a consequence, small mortality effects have large impacts on public expenditures: in the U.S., an extra year of living would increase outlays by, at least, the annual size of Medicare and Social Security, about one-third of total federal expenditures. Understanding the impact of such programs on investment in health is thereby important for assessing the relationship between the dramatic increase in old-age life-expectancy, the postwar growth in mandatory annuity programs, and the rapid development of medical care to extend the length of life.

In this paper we study the impact of mortality contingent claims on savings and investment in health human capital. Mortality contingent claims are defined as any type of financial arrangements that generate income dependent on the length of one's life and include, for example, annuities, life-insurance,

\footnotetext{
${ }^{1}$ We are thankful to Michael Boozer, David Bradford, Paul Gertler, James Heckman, Magnus Johannesson, Casey Mulligan, Sherwin Rosen, Jose Scheinkman, as well as seminar participants at the University of Chicago, NBER Summer Institute on Social Insurance, the 7th Annual Health Economics Conference at Boston University, the Stockholm School of Economics, and the Western Economic Association Meetings for comments. John Cawley and Tom Lawless provided valuable research assistance. Financial support for this project was provided by the John M. Olin Foundation, to which both authors are thankful.

${ }^{2}$ For the median household in the U.S., public annuities are the biggest component of wealth: about 60 percent of median wealth is social security wealth, about 25 percent housing, with the remainder being partly annuitized through private pensions.

${ }^{3}$ See, e.g., Older Workers, Retirement, and Pensions (1995), U.S. Department of Commerce, Economics and Statistics Administration, Bureau of the Census, and LifeSustaining Technologies and the Elderly (1987), Office of Technology Assessment, Congress of the United States, Washington, D.C.
} 
reverse mortgages, and various forms of survivor benefits in pension plans. Our main argument is that mortality contingent claims have important incentive effects on investments in health and that these incentives raise a rich set of unexplored questions. Although conventional analysis of these issues ${ }^{4}$ by economists assumes mortality to be exogenously determined, and thus not affected by health investments, we argue that the rapid increases in expenditures on medical care inputs is very hard to interpret without treating mortality as endogenous. A major point we stress is that under such endogenous mortality, there are feed-back effects between the two largest public programs in many countries - health care services and old-age annuities; Medicare and Social Security in the US.

Section 2 sets forth our basic model of life-extension, in which length of life may be extended through costly medical care or other resources. Many economists seem to stress that since medical care is often highly subsidized, maximum life-extension will always take place when feasible. This ignores that extending life involves large private costs such as e.g. reduced quality of life (e.g., pain), foregone bequests, and time transfers from spouses or children. Other costs include life-extending lifestyles, diets, prescriptions, or experimental therapies, which also contribute to costs beyond simply subsidized hospital and physician services. ${ }^{5}$ These private costs affects the tradeoff between living well versus living long because life-extension reduces resources available for consumption but increases the time to consume. We argue that this tradeoff is central for assessing the impact of mortality contingent claims on savings or investments in health.

When a claim is contingent on mortality alone, it is incomplete with respect to morbidity and we consider the effects of this incompleteness on life-extension. First, we argue that public annuities induce excessive lifeexpectancy. An extreme, but illustrative, example of this incentive effect is financing the co-payment for a person's life-support machine with his Social Security pay. More generally, annuities are piece-rate incentives for life-extending health investments. As a consequence, mandatory annuities have some unrecognized welfare losses because they distort life-expectancy upwards as a life is more valuable to extend when one has not run out of

\footnotetext{
${ }^{4}$ See e.g. the references in Kotlikoff (1989), Hurd (1990), or Posner (1995).

${ }^{5}$ Indeed, the fact that sellers of annuities and life-insurance do not price discriminate medical insurance or living wills but do discriminate on behavior not related to medical care (e.g., smoking) also suggests that there is a large behavioral component in life-extension.
} 
savings. Second, if income is more valuable when healthy than when sick), the morbidity incompleteness of annuities implies that a very sick individual has nothing better to spend annuitized income on than futile attempts to improve his health. ${ }^{6}$ These two annuity-induced effects on health investments, we believe, are particularly relevant to the recent explosion in mandatory annuity incomes, health care outlays, and life-expectancy at the end of life.

Section 3 considers the non-standard interactions between public and private savings under a Pay-As-You-Go (PAYG) Social Security program under endogenous mortality. Contrary to the case when mortality is exogenous, our model explains why private savings may respond positively to expansions in mandatory savings programs. ${ }^{7}$ An important factor determining the complementary nature of private and public savings is whether the public savings are life-extending. If they are, more private savings may be needed to finance old age living. A somewhat self-evident example is mandatory savings for health care, such as Medicare in the U.S. By taxing the young for the care of the elderly, such programs extend life beyond that which would be observed in a free market. Private savings may therefore be increased to finance a longer life in old age.

Furthermore, life-extending savings programs such as Medicare interact positively with other programs dependent on the length of life, such as Social Security. Thus, if the co-payment rate for Medicare were lowered, then this would presumably raise Social Security outlays through longer living. The incentives of life-extension imply a feed-back effect in the opposing direction as well: if annuity levels rise, the increases in medical care would take place. This feed back, in turn, would raise the annuity outlays even more. In other words, not only does subsidizing health care increase expenditures on social security by extending life, but expanding social security also increases health care outlays by raising the income rewards for living. Moreover, this feedback

\footnotetext{
${ }^{6}$ The extreme form of a private demand for transfers away from sick states is through so called advance directives, which limit medical care in disabling states, many times to secure bequests.

${ }^{7}$ There is a substantial literature on the effects of the low substitutability of non-pension and pension savings. Cagan (1965) and Katona (1965) show that the extensive margin, whether having pensions or not, affects non-pension savings positively. Green (1981) and King and Dicks-Mireaux (1982) document these effects on the intensive margin as well, and Poterba et al. (1996) find these effects robust to controlling for individual fixed effects and a range of potential substitutes.
} 
arises for empirically relevant parameters in the US. In particular, Tengs et al. (1995) review about 500 studies on interventions to extend life and find that the median total cost for extending life by one year was about $\$ 20,000$. Subsidized at a Medicare rate of $80 \%$, this would imply a cost of about $\$ 4,000$, which is far below the annual Social Security benefits for many individuals. ${ }^{8}$

We show in section 4 how the incentives of life-extension affect the demand for annuities and argue that non-indexed annuities, where real income falls with length of life, may involve efficiency gains by discouraging life-extension. Due to the life-extension feedbacks of annuities, the competitive pricing of them implies that unit prices rise with quantity. We illustrate how to measure such feedback effects of public annuities using aggregate data from a public pension program in the US, The Civil Service Retirement System (CSRS). Finally, section 6 concludes.

Our results imply that the advantages of annuities, and therefore the case for them being provided by the public sector, have been overstated. ${ }^{9}$ The case has been made in models of exogenous mortality, but those models fail to explain the large amount of medical care devoted towards life-extension and therefore only consider the advantages of annuities in insuring against depletion of savings. By expanding the domain of a relatively scarce literature on the determinants of endogenous lifetime (see, e.g., Grossman (1972), Ehrlich and Chuma (1990), and especially Rosen (1989, 1995)), we show how the traditional analysis is altered when mortality contingent claims affect mortality.

\section{Rational Life-Extension and Annuities}

This section sets out the basic incentives that are important for life-extension when wealth is tied to length of life through mortality contingent claims.

\subsection{Mortality Contingent Claims Under Certainty}

We consider a non-working retired individual with an increasing and strictly concave instantaneous utility function $U(c)$. Consider allocating a lump-sum

\footnotetext{
${ }^{8}$ Moreover, in the US private pensions increase the benefit, and Medigap coverage reduces the cost in this tradeoff.

${ }^{9}$ See, e.g., the classic article by Yaari (1965).
} 
of retirement wealth $W$ over a remaining life of $T$ years after retirement. The indirect utility $V(W, T)$ obtained by optimally choosing consumption subject to the wealth constraint is

$$
V(W, T)=M a x_{c} \int_{t=0}^{T} U(c(t)) e^{-r t} d t
$$

subject to

$$
\int_{t=0}^{T} c(t) e^{-r t} d t \leq W
$$

where $r$ is the discount rate throughout, assumed to be equal to the interest rate. The solution to the consumption problem in this case is well known; it involves perfect consumption smoothing in the sense of equalizing yearly consumption levels. The lump-sum wealth is split equally across years to give the annual consumption level $c(t)=W / A[T]$, where $A[T]$ is the present value of a security paying one-dollar every year until $T .{ }^{10}$ Substituting in the annual consumption level yields

$$
V(W, T)=A[T] U\left(\frac{W}{A[T]}\right) .
$$

This implies that the length of life is complementary to wealth (i.e., $V_{T W} \geq 0$ ) because the poorer is the individual, the less does he consume when extending life. Put more simply, if one runs out of savings, one does not have much of a life to extend.

Denote by $M$ the resources devoted towards extending life, which includes not only medical care (e.g., hospital and physician services), but also other resources such as dietary expenditures, home care outlays, and time transfers from children or a spouse. If such care extends life according to the weakly increasing and concave technology $T(M)$, it introduces a tradeoff between the quantity and quality of life as represented by years lived $T$ and annual consumption $c .{ }^{11}$ Yearly consumption falls when investing in life-extension because less wealth is spread over more years. If this is represented by the

\footnotetext{
${ }^{10}$ This value is determined by $A[T]=\int_{t=0}^{T} e^{-r t} d t$.

${ }^{11}$ This technological relationship relates to the frequently estimated quantities of 'lifeyears-saved' of medical interventions (see, e.g., World Bank (1993) and Tengs et al. (1995)). In order to maintain the focus on life-extension, we do not consider more elaborate health production functions.
} 
overall utility $V(W-M, T(M))$, the demand for care balances the value from extending life to the loss in quality of life from foregone consumption spent on care:

$$
V_{T} T_{M}=V_{W}
$$

For a mortality contingent claim, we denote by $W(T)$ the wealth that is associated with a given lifetime $T$. This now implies the indirect utility $V(W(T(M))-M, T(M))$, and the demand for life-extending resources has now been altered. The necessary first-order condition is now

$$
T_{M}\left[V_{W} W_{T}+V_{T}\right]=V_{W}
$$

The left-hand side is the marginal benefit of extra resources devoted to lifeextension. Now, however, this is not only made up of the direct effect of enjoyment of living, but also the indirect effect of income contingent on living (i.e., the mortality contingent claim). The right-hand side is, as before, the marginal cost of foregone consumption due to life-extending care.

The point is not that individuals may make a profit from living, but rather that the marginal benefit of life-extension has been increased. Consider the case of partial annuitization, ${ }^{12}$ when the overall wealth is given by the nonannuitized wealth, $Y_{0}$, together with the amount of annual annuity earning, $Y_{1}$, multiplied by the number of years lived,

$$
W(T)=Y_{0}+Y_{1} T
$$

In this case, the marginal wealth impact of life-extension equals the annual annuity pay: $W_{T}=Y_{1}$. When annuitized, the individual does not have to about financing future years of living because the quality-quantity tradeoff has been altered. To illustrate, consider the annual consumption level when fully annuitized $\left(Y_{0}=0\right)$, as in

$$
c(t)=\frac{Y_{1} T(M)-M}{T(M)}=Y_{1}-\frac{M}{T(M)} .
$$

The yearly consumption level is now made up of the annuity income, less the yearly care used to extend life. The key point is that life-extension is

\footnotetext{
${ }^{12}$ We here focus on the ex-post decision, when the annuity is provided through a PayAs-You-Go program, but we later consider private markets for annuities in which lifeextending efforts are priced out.
} 
cheap because extending life generates more annuity receipts to finance the life-extending care. Indeed, if $T(M)$ is elastic, then both the quantity and quality of life increase with care. The individual lives longer and enjoys more consumption when extending life. ${ }^{13}$

These annuity incentives imply that, holding overall wealth constant, lifeextension is excessive relative to lump-sum savings when annuitized. Figure 1 below indicates the opportunity sets in terms of feasible combinations of wealth and lifetime $(W, T)$ for a non-annuitized and an annuitized individual. The annuitized opportunity set ranges from $\left(Y_{0}+Y_{1} T(0), T(0)\right)$, when all wealth is consumed, to $(0, T(\bar{M})$, when all wealth is allocated towards lifeextension and $\bar{M}$ is the maximum feasible level of care defined by annuity revenues equaling care outlays, $Y_{0}+Y_{1} T(\bar{M})-\bar{M}=0$. More wealth has to be given up for an extra year of life when there are no annuities because life-extension is not wealth generating. This implies that the slope of the frontier of feasible wealth and life-length combinations is steeper for the nonannuitized individual.

Now consider the optimal combination when annuitized, as denoted by $\left(W_{A}, T_{A}\right)$. If the individual faces the lump-sum tradeoff, as given by the nonannuitized opportunity set, then he will reduce life-extension and increase consumption by choosing $\left(W_{N}, T_{N}\right)$ instead of $\left(W_{A}, T_{A}\right)$. The fact that the two opportunity sets cross at the optimal annuity combination means that the lump-sum wealth is the same as that of the annuitized individual. In other words, the difference in life-extending care is not due to wealth. The tradeoff that is less steep, in terms of foregone wealth when annuitized, naturally makes him shift towards greater quantity, relative to quality of life: the distorted life-length under the annuity is $T_{A}-T_{N}$.

\footnotetext{
${ }^{13}$ Naturally, as discussed below, this gets priced out in a private annuity market in terms of larger premia. It may even be that without commitment devices, such as caps on Medicare outlays, a private annuity market breaks down. This would be the case when a life-support machine could be financed by Social Security, leaving some residual amount of resources left over, perhaps for the partner of the life-extender.
} 


\subsection{Mortality Contingent Claims Under Uncertainty}

The same incentives are present under uncertainty, when annuities and other mortality contingent claims fill the important role of insuring against depletion of savings. Let uncertainty be represented by a set of health states $h=$ $1,2, . ., H$, where health states represent a given disease or illness condition. ${ }^{14}$ Under a lump-sum claim that pays off $W_{h}$ in state $h$, the individual devotes resources $M_{h}$ under the incentives discussed in the previous section. The ex-ante problem is therefore to allocate state contingent wealth $W_{h}$ to solve

$$
\operatorname{Max} \sum_{h=1}^{H} \pi_{h} V\left(W_{h}-M_{h}\left(W_{h}\right), T_{h}\left(M_{h}\left(W_{h}\right)\right)\right) \quad \text { s.t. } \quad \sum \pi_{h} W_{h} \leq W,
$$

where $M\left(W_{h}\right)$ is the demand for life-extending resources in a state, $\pi_{h}$ is the probability of the state occurring, and $W$ is ex-ante wealth. The pure insurance benefit of an annuity is well known, and is the exclusive focus of discussions concerning exogenous mortality. It applies in our case when life-extension efforts are completely unproductive, so that $\partial T_{h} / \partial M_{h}=0$, implying that no resources are given up for care, $M_{h}=0$. In this case, the familiar condition for optimal insurance requires that all gains from trade across states are exploited, implying that annual consumption levels without lifeextending care are equalized across states at the level $W_{h} / A\left[T_{h}(0)\right]$. Hence, an annuity providing this consumption guarantees optimal consumption. ${ }^{15}$

The life-expectancy under state-contingent care $M \equiv\left(M_{1}, . ., M_{H}\right)$ is

$$
E[T \mid M] \equiv \sum \pi_{h} T_{h}\left(M_{h}\right)
$$

Annuities makes such life-expectancy excessive relative to lump-sum pay, even when they serve the role of insuring against depleted savings. More precisely, for any annuity contract, there exists a state-contingent claim of equal present value under which life-expectancy is lowered but individuals are better off. To show this in a similar way to the deterministic case, for an annuity of size $Y$, let the state contingent wealth under annuity-dependent care $M_{h}(Y)$ be denoted by

$$
W_{h}=T_{h}\left(M_{h}(Y)\right) Y .
$$

\footnotetext{
${ }^{14}$ For example, those classified by DRGs under Medicare in the U.S.

${ }^{15}$ Formally, this follows from the marginal indirect utility of wealth given by $V_{W}=$ $U^{\prime}\left(W_{h} / A\left[T_{h}(0)\right]\right)$, which, together with the first order condition $\pi_{h} V_{W}=\pi_{h} \lambda$ (where $\lambda$ is the Lagrange multiplier), yields that $W_{h} / A\left[T_{h}[0]\right.$ is equal across states.
} 
Since annuities increase the marginal benefit of life-extension, we know that the life-extending resources under the annuity are larger than under lumpsum pay: $M(Y) \geq M\left(W_{h}\right)$. Therefore, for all states, receiving the lump-sum wealth $W_{h}$ requires the same expenditures ex-ante, $\sum \pi_{h} W_{h}=E[T \mid M(Y)] Y$, but less- life extension in each state. This reduction in life-extending care relative to annuities makes the individual better off in each state but reduces life expectancy,

$$
E[T \mid M(Y)] \geq E[T \mid M(W)] .
$$

In sum, annuities involve excessive life-extension relative to complete, state contingent contracts, even when they are serving the role of insurance against depleted savings. The effect discussed here is that observed when holding wealth constant, but equally important may be the effect that occurs due to the wealth effects generated by public transfers across generations.

The excess extension of annuities relative to lump-sum pay is particularly important when utility is state-dependent, in the sense that the marginal benefit from income is positively related to health so that income is less valuable when sick. This is because annuities are only mortality contingent, and not morbidity or health contingent. If $Y_{h}(T)$ is the amount of the annuity in health state $h$ under life-length $T$, this is represented by the health incompleteness $Y_{h}(T)=Y_{h^{\prime}}(T)$. When income is valued more when healthy, other things constant, the individual would want more resources when in good health, rather than bad health. This is the opposite transfer of traditional health insurance, which is actually 'sick insurance'. If better health increases the marginal utility of income, there are gains from trade across future health states, when the utility loss from the foregone income when sick is less than the utility gain of the same income when healthy. However, since annuities are not health-dependent, there are excess resources when sick, which are therefore devoted to life-extension: a sick individual with a large annuity has nothing else to spend it on other than excessive medical care. Consider two health states, sick and healthy, denoted $h=0$ and $h=1$ representing sick and healthy, and let $\left(Y_{0}, Y_{1}\right)$ be the hypothetical annuity amounts held in the two morbidity states. Assume that life-extension is only productive when sick, in which case any redistribution away from the sick state towards the healthy state reduces the overall life-expectancy,

$$
E\left[T \mid Y_{0}, Y_{1}\right]=\pi_{0} T\left(M_{0}\left(Y_{0}\right)\right)+\pi_{1} T\left(M_{1}\left(Y_{1}\right)\right) .
$$


Life-extending care in the sick state is larger, the larger is the annuity and the larger is the loss in marginal utility of consumption from sickness. Even if the productivity of life-extension under a treatment is very low, substantial expenditures may be made because the value of the income foregone is also low when sick. This will often imply that optimal demand for the annuity that is complete with respect to morbidity requires $Y_{1}>Y_{0}$, which is impossible for incomplete annuities requiring $Y_{1}=Y_{0}$ and, hence, longer living in this case.

\subsection{Life-Extension In Altruistic Families}

There may be several people investing in one person's life, as would be the case, for example, if children are longer living or a younger wife invests in the life-extension of a husband. The investments may be made in cash but also in-kind, the latter taking place through shared housing or time transfers. Although out-of-pocket expenses are non-trivial for individuals above $65,{ }^{16}$ the largest component of private resources appear to be actual time allocated towards private care, whether by children, spouses, or the person herself. ${ }^{17}$ Under multi-person life-extension, principal-agent issues arise when the person whose life is being extended is not undertaking the costly care. The important point here is that mortality contingent claims may affect the degree to which the preferences of the agent and the dependent principal line up, in particular when the agent is altruistic towards the principal. ${ }^{18}$

Consider the common case of a male annuity of size $Y_{m}$, which has survival benefit to the female of $S_{f}$, in which case the after care wealth under no discounting is

$$
W=Y_{m} T^{m}+\operatorname{Max}\left\{S_{f}\left(T^{f}-T^{m}\right), 0\right\}-M_{m}-M_{f}
$$

\footnotetext{
${ }^{16}$ Out-of-pocket expenditures constituted more than 20 percent of income for more than 10 percent of elderly in 1977 and 1987 in the National Medical Care Expenditure Survey (NMES) (see Taylor and Banthin (1994)).

${ }^{17}$ Shroeni and McGarry (1995) discuss evidence concerning the magnitude of such time transfers in a recent US survey.

${ }^{18}$ The extreme, but illustrative, version of this argument is the routine investigation of life-insurance beneficiaries in homicide cases.
} 
The effect on it of extending the life of the male is thus

$$
\frac{d W}{d M_{m}}=\left[Y_{m}-1_{\left\{T^{m} \leq T^{f}\right\}} S_{f}\right] \frac{d T^{m}}{d M_{m}}-1
$$

which derives from the fact that an extra year of male living generates one more year of annuity pay, but, if the male is outlived by the female, one less year of survivor benefits. Therefore, life-insurance of the female lowers the income gain from life-extension. ${ }^{19}$ Dependent on the altruism of the female spouse, the observed under-insurance of widows may provide an efficiency gain in generating male life-extension. We would expect couples with more altruism, perhaps as reflected by a longer duration of marriage, to more fully insure the wife against the death of the husband because in more altruistic couples less of an income motive is needed.

More generally, when more than one life is extended, let $V\left(W, T^{m}, T^{f}\right)$ denote the indirect utility for a given family wealth and given lifetimes of the male and female, defined similarly to the single-life case. ${ }^{20}$ It is the value of optimal consumption for a given wealth level and length of life of both partners in the couple. When there is no discounting and differential annuities of size $Y_{m}$ for the male and $Y_{f}$ for the female, the total wealth is

$$
W=Y_{m} T^{m}+Y_{f} T^{f}-M^{m}-M^{f}
$$

The marginal effects of life-extension on wealth are, in this case, simply $Y_{m}$ and $Y_{f}$ for the male and female. This can easily be shown to imply that, even though there may no gender interaction in the effectiveness of medical care on life-extension, more expenditures are made on the male when his annuity is larger. ${ }^{21}$

\footnotetext{
${ }^{19}$ Note that this implies that providing survival benefits to public and private annuities may have small, or even negative, effects on total annuity outlays dependent on the relative size of the increase in outlays on the agent and the decrease in outlays on the principal.

${ }^{20}$ More precisely, it may be defined according to $V\left(W, T^{m}, T^{f}\right) \equiv \operatorname{Max} \alpha \int_{t=0}^{T^{f}} U_{f}\left(c_{f}(t)\right) e^{-r t} d t+(1-\alpha) \int_{t=0}^{T^{m}} U_{m}\left(c_{m}(t)\right) e^{-r t} d t$ subject to $\int_{t=0}^{T^{f}} c_{f}(t) e^{-r t} d t+\int_{t=0}^{T^{m}} c_{m}(t) e^{-\tau t} d t \leq W$, where $\alpha$ is the relative weight of the female.

${ }^{t \overline{2}}{ }^{1}$ Consequently, pharmaceuticals should be expected to tailor research towards the feminist agenda as the annuity levels across genders converge.
} 


\section{Aggregate Implications for Public Savings and Health}

This section considers the non-standard interactions between public and private savings under endogenous life-extension when the public program is financed in a Pay-As-You-Go (PAYG) manner, as well as the interactions that occur between such public savings programs and those programs for health.

We consider the effects of a PAYG-financed mandatory annuity program under no discounting. Let $L$ and $T$ denote the total years of work and retirement, where the first is assumed exogenous but the second is affected by our discussed life-extension incentives. Consider a population where each individual lives $L+T$ years. With a stationary level of fertility of $N$ individuals born every year, the age distribution is stationary with $N$ individuals in every age cohort. At every period, the total number of workers is therefore $N L$ and the total number of retired individuals is $N T$, with the corresponding dependency ratio for the population (i.e., number of non-workers per worker) $\delta=N T / N L$. Let the yearly after-tax earnings be $W(1-\tau)$ during working years, and let the annuity level and medical care in retirement be $Y$ and $M(Y)$, so that when total life-time income is smoothed out over all years of living this gives the annual consumption level

$$
C=\frac{L W(1-\tau)+T Y-M(Y)}{L+T}=\rho(Y) W(1-\tau)+[1-\rho(Y)] Y-m(Y),
$$

where $m(Y) \equiv M(Y) /(L+T)$ is the medical care smoothed out over time and $\rho(Y) \equiv L /(L+T)=1 /(1+\delta(Y))$ is the fraction of life spent working and is a negative function of the dependency ratio. Annual consumption net of care is thereby determined by the wedge between working and retirement income. The implied savings $S$ during working years is given by

$$
S=W(1-\tau)-C=(1-\rho(Y))[W(1-\tau)-Y]+m(Y) .
$$

To smooth income, savings increase with the number of retirement years to be financed relative to working years, with the gap between working and retirement income, and with the amount of old age medical care. If the PAYG Social Security program is balanced, then we have that the tax-rate $\tau(Y)$ is 
implicitly defined by the annuity level $Y$ when revenues of the program equal its expenditures, as in

$$
N W \tau(Y) L=N T Y \Rightarrow \tau(Y)=\delta(Y)\left(\frac{Y}{W}\right)
$$

This implies that when the dependency ratio depends positively on the the annuity level, $d \delta / d Y \geq 0$, the increase in taxes needed to finance an increase in the level of annuity income is strengthened, because, in addition to simply requiring larger funds holding the age distribution constant, annuities increase the number of individuals eligible to receive payments,

$$
\frac{d \tau}{d Y}=\frac{\tau(Y)}{W}+\frac{d \delta(Y)}{d Y}\left(\frac{Y}{W}\right) \geq 0
$$

Using this effect of annuities on taxes, the effect of raising the mandatory annuity level on savings is given by

$$
\frac{d S}{d Y}=(1-\rho(Y))\left[W\left(-\frac{d \tau}{d Y}\right)-1\right]-\frac{d \rho}{d Y}[W(1-\tau)-Y]+\frac{d m}{d Y} .
$$

The first negative effect is induced by the reduction in the gap between pre- and post-retirement income. The second positive effect is non-standard and results from the change in the age distribution caused by the increased incentives of life-extension generated by the annuity increase. Savings increase because the person will live longer when incentives for life-extension are increased. The third effect is positive as well and is due to the increased medical care induced by a larger incentive to extend life. This implies that a mandatory annuity program may have a low, or even positive, impact on private savings. The complementarity between public and private savings, or private pensions and private savings outside pensions, has been shown to be of empirical importance but is inconsistent with traditional life-cycle analysis. $^{22}$ As this analysis shows, however, this conclusion is due to exogenous mortality; if life-extension is affected by the piece-rates for living induced by annuities, a complementarity between public and private savings may be present.

\footnotetext{
${ }^{22}$ See the references in the introduction.
} 


\subsection{Public Annuity and Health Care Programs}

Subsidization of medical care interacts in important ways with the discussed incentive effects of annuities. Most public health subsidy programs seem to amount to mandatory health care savings since relatively larger taxes are levied on the working young and relatively larger subsidies are paid to the sicker old. Our results imply that public mandatory medical savings may be complementary with private savings. To determine the savings effects of subsidizing life-extending medical care, let $f$ denote the fraction of care subsidized, and consider a demand function for medical care as a function of health subsidies and annuity benefits $M(f, Y)$ such that, ceteris paribus, it responds positively to both incentives for care: $d M / d f, d M / d Y \geq 0$. The central aspect of such subsidies is that they interact positively with the excess extension of life induced by annuities, since the medical costs to be spread across years of living are reduced. In other words, the larger are the medical care subsidies, the larger is the discussed incentive effect of annuities, since the annuities drive the benefit of extension and subsidies lower the cost of such extension. Therefore, they may interact positively, so that the annuity effect on medical care is determined by the level of the subsidy: $d^{2} M / d f d Y \geq$ 0 . Suppose that the budget for medical care and Social Security is balanced, as in

$$
N T[M(f, Y) f+Y]=N L W \tau,
$$

with the previous special case of no public medical care being obtained when $f=0$. The tax rate that finances both the health and Social Security programs is determined by

$$
\tau(f, Y)=\delta(f, Y) \frac{M(f, Y) f+Y}{W} .
$$

Increasing medical subsidies or annuities has two positive effects on the tax rate, one being the direct effect due to increased expenditures under a constant age distribution and the other being the indirect effect through the aging of the population under increased incentives for life-extension: $\tau_{f}, \tau_{Y} \geq 0$. By arguments similar to those made above, the annual consumption level under the two programs is

$$
C=\frac{L W(1-\tau)+T Y-(1-f) M(f, Y)}{L+T}
$$


with the corresponding savings per year worked

$$
S=W(1-\tau)-C=(1-\rho(f, Y))[W(1-\tau(f, Y))-Y]+m(f, Y),
$$

where $m(f, Y) \equiv(1-f) M(f, Y) /(L+T)$ is the non-subsidized part of medical expenditure smoothed out over time. The effect of increasing the medical subsidy on savings is therefore

$$
\frac{d S}{d f}=(1-\rho(Y)) W\left(-\frac{d \tau}{d f}\right)-\frac{d \rho}{d f}[W(1-\tau)-Y]+\frac{d m}{d f} .
$$

The first two terms are similar to before: the direct negative savings is due to lower after-tax earnings and the positive effect is due to increased lifeextension under medical subsidies. The second effect is again through the change in the age distribution. The third and last term reflects how much medical expenditures increase due to the increase in the subsidy; it may be positive or negative, depending on whether or not medical care is elastic. This implies that an increase in medical subsidies during old age may increase private savings. Indeed, this may even be true if the lifetime is exogenous, since if the rise in the subsidy increases outlays, then more money is needed during old age.

The interesting fact is that the two programs interact in total outlays. When mortality is endogenous, medical subsidies affect annuity outlays since productive medical care implies that an individual must be paid on his annuity longer: if the co-payment rate for Medicare in the U.S. were to be lowered, then Social Security outlays would presumably increase. Furthermore, there are indirect effects in the opposite direction as well. If annuity levels were to be increased, then medical care expenditures would increase as well, due to the increased benefit of life-extension when annuities raise the income rewards for living. ${ }^{23}$ More precisely, the first effect of medical subsidies on the outlays of the Social Security program is given by

$$
\frac{d \tau}{d f}=N Y \frac{d T}{d f} \geq 0
$$

\footnotetext{
${ }^{23}$ Our arguments are based on the substitution effects generated by the interactions between these programs in a stationary age distribution. Of equal importance may also be the wealth effect induced by richer old people that is generated by programs that transfer resources between age cohorts under a non-stationary age distribution. For example, if younger cohorts pay relatively more for their annuities than older ones in the U.S., and if medical care is a normal good, then Social Security may increase medical care relatively more for the older generation than for the younger generation.
} 
and is due to the fact that larger outlays occur when people live longer. The second effect that Social Security outlays have on medical care is due to the larger life-extension incentives, as in

$$
\frac{d(N f T M)}{d Y}=N f\left[T \frac{d M}{d Y}+\frac{d T}{d Y} M\right] \geq 0 .
$$

\section{Implications for Private Mortality Con- tingent Claims Markets}

This section discusses the implications of our arguments for private markets for mortality contingent claims in terms of limiting the life-extension induced by annuities and the price effects of such incentives.

\subsection{Efficiency and Indexation}

In competitive insurance markets, where prices are driven down to minimum average costs, fair prices obtain. Consider the illustrative case of no discounting when the price $p(Y, M)$ of an annuity of size $Y$ under care $M$ is given by

$$
p(Y, M)=\sum \pi_{h} T_{h}\left(M_{h}\right) Y=Y E[T \mid M] .
$$

This is simply quantity times the unit price equalling the life-expectancy of the demander. The classic moral hazard problem induced by annuities is that the harm imposed on those paying the premium by life-extension is not internalized. In particular, at the time of life-extension, this is determined by the indirect utility $V\left(Y T_{h}-M_{h}-p, T_{h}\right)$ without taking into account the effect on the premium $p$. Optimal care balances, as before, the benefit from income and living against the cost in foregone consumption, as in

$$
\frac{d T_{h}}{d M_{h}}\left[V_{W} Y+V_{T}\right]=V_{W}
$$

On the other hand, the socially efficient level of care is determined by taking into account how the annuity price is affected by this same change in care, as in

$$
\pi_{h} \frac{d T_{h}}{d M_{h}}\left[V_{W} Y+V_{T}-V_{W}\right]=\frac{d p}{d M_{h}} \sum \pi_{k} V_{W}
$$


This balances the social benefits of those that end up in the health state (the left-hand side) with the social cost it imposes on others in terms of a larger premia (the right-hand side). Since private incentives imply that the lefthand side is zero, efficient provision reduces life-extension in order to avoid the negative external effects it has on others paying the premia.

Private markets may internalize such external effects. The efficient 'tax' on life-extenders makes them pay the marginal harm imposed on all premium payers. If $\theta_{h}$ is the tax-rate, then $\theta_{h} M_{h}$ is the Pigouvian tax bill for lifeextending care. It should be set to equate the social cost with the social benefit above, as in

$$
\theta_{h}=\frac{1}{\pi_{h}} \frac{d p}{d M_{h}} \sum \pi_{h} V_{W}
$$

This is the harm (on the margin) imposed on those not ending up in the state by the premium increase induced by their life-extending care. A method of mimicking this tax on unobservable care would be through decreasing the income rewards of life-extension through a non-indexed annuity in which the real annual pay fell with the length of life. A lack of indexing would discriminate within a given cohort, in contrast to conventional age discrimination in annuity premia which operates across cohorts. ${ }^{24}$

\subsection{Competitive Pricing}

The conventional analysis in which care is unproductive and mortality exogenous implies linear pricing; that is, unit prices do not change with the quantity of annuities purchased since life-expectancy is unaffected. On the other hand, consider the case when the distribution of lifetimes on a higher quantity of annuities dominates one of a lower quantity in the first-order

\footnotetext{
${ }^{24}$ More precisely, when the annuity is not indexed, it pays out the decreasing real annual pay fraction $R(T) Y$ at age $T$, where $0 \leq R(T) \leq 1$ and $R_{T} \leq 0$. The marginal condition ex-post at the time of care therefore becomes

$$
\frac{d T_{h}}{d M_{h}}\left[V_{W} Y\left[1+R_{T}\right]+V_{T}\right]=V_{W},
$$

which reduces the marginal benefit of life-extension since the factor $\left[1+R_{T}\right]$ is less than unity, the value it takes when indexed.
} 
sense. In this case, unit prices $p_{U} \equiv p / Y$ rise with quantity, as in

$$
\frac{d p_{U}}{d Y}=\frac{d E[T \mid M(Y)]}{d Y} \geq 0
$$

In other words, prices are non-linear: unit prices rise with quantity as it raises the life-extension and consequently the outlays of the insurer; the larger is the annuity effect on survival, the larger is the positive effect of quantity on unit price.

Unfair pricing above expected claims may make unit prices fall with quantity. However, there would still be different predictions between exogenous and endogenous mortality. In particular, assume that prices satisfy

$$
p(Y \mid \phi)=\phi_{0}+\phi_{1} Y E[T \mid M(Y)]
$$

where $\phi=\left(\phi_{0}, \phi_{1}\right)$ are fixed and variable costs adding to the premia beyond just expected claims. This implies the unit price

$$
p_{U}(Y \mid \phi)=\frac{\phi_{0}}{Y}+p_{U}(Y \mid \phi=0) .
$$

Now, under exogenous mortality, unit prices fall with quantity as the fixed costs are spread over a larger sized contract:

$$
\frac{d E[T \mid M(Y)]}{d Y}=0 \Rightarrow \frac{d p_{U}}{d Y} \leq 0 .
$$

On the other hand, under elastic endogenous mortality, there exists a quantity $A$ above which unit prices are rising, although they may be falling initially, because the fixed costs become negligible at larger quantities, ${ }^{25}$

$$
\frac{d p_{U}}{d Y} \geq 0, Y \geq A
$$

Furthermore, two observable groups that differ in the size of the incentive effect will have different relationships between unit price and quantity, although not necessarily a positive one. For example, as the life expectancy of a young cohort is less elastic than that of an older one, we predict a positive age interaction on the quantity-unit price relationship; prices for

\footnotetext{
${ }^{25}$ This follows directly from the expression for $\frac{d p U}{d Y}$.
} 
older cohorts have larger effects of quantity on unit price, even though the relationship may not be positive, due to fixed costs.

Our life-extension incentives imply that prices for so called guaranteed annuities have predictable price differences relative to standard annuities. Such annuities guarantee an annual pay of $Y$ for at least $T_{0}$ years, after which the annuity works in the standard way. This mortality contingent claim differs from a standard annuity in that the marginal benefit from lifeextension is lowered. The price of a guaranteed annuity would be

$$
p_{G}(Y)=Y\left(T_{0}+P\left(T \geq T_{0}\right) E\left[T \mid T \geq T_{0}\right]\right) .
$$

If the survival function under the two contracts were the same, the difference in total price between the regular and guaranteed annuity would be

$$
p_{G}(Y)-p(Y)=Y \int_{t=0}^{T_{0}}(1-S(t)) d t
$$

This is because the guaranteed annuity is like paying a regular annuity to an individual that lives with certainty during the guarantee period. However, relative to the normal annuity, the marginal effect of life-extension is lower under a guaranteed annuity, which consequently implies that the premium for a guarantee should be less than the difference above, due to the reduction in life-extension under guaranteed income.

Finally, the same arguments can be used to predict the premium for indexing. Our incentives imply that indexing should affect unit prices in predictable ways. In particular, indexing should increase the cost of annuities more than the expected cost of inflation since it implies larger incentives to extend life.

\subsection{Measuring The Feed-Back Effect of Annuities}

This section illustrates how to empirically assess the feedback effects of annuities using standard aggregate data generated by an annuity roll. We use data reported in Virga (1996) on the public pension program covering federal employees in the U.S. who were hired before 1983, The Civil Service Retirement System (CSRS). Figure 2 below shows survival functions for groups differing in the amount of monthly annuity pay they received while on that pension roll. The data cover the fiscal years 1988-94 and are differentiated by five levels of monthly annuity levels. 
The annuities under CSRS are indexed relative to the CPI and are mandatory so that selection-issues are presumably of minor importance ${ }^{26}$ The sizes of these annuities are relatively large, as they combine Social Security and a federal employee pension program. The data reported in Virga (1996) were presented in terms of yearly mortality hazard rates on the annuity role represented by CSRS across salary and annuity cells, with exceptionally large cell sizes ranging from about 1500 to 1.8 million. The data show that yearly mortality hazards fall with annuity level and salary, each falling when controlling for the other. The lowest yearly hazard rates are about one-half of the highest, across all cells. We used these hazard rates to compute the annuity-dependent survival curves reported in the figure. ${ }^{27}$ The plotted survivals are for males, conditional on reaching age 57 , and they display the positive relationship between annuity pay and survival discussed above.

Although these patterns may, of course, be confounded, the data reported by Virga show that they hold controlling for gender and salary levels, as well. However, the key point of these survivals is to illustrate how relatively small differences in survivals may nevertheless lead to relatively large incentive effects. To compute these incentive effects, we decomposed the price increase of an annuity due to an increase in quantity into two components: one holding unit price constant and the other holding quantity constant, as in

$$
d p(Y)=p_{U}(Y) d Y+Y d p_{U}(Y)
$$

Dividing through by the increase in the total annuity value, the relative contributions are obtained, as in

$$
1=\frac{Y d p_{U}(Y)}{d p(Y)}+\frac{p_{U}(Y) d Y}{d p(Y)} .
$$

We call the first term the incentive component of the increase in the annuity value resulting from the increase in the unit price and the second term the quantity component resulting from the increase in the quantity alone.

\footnotetext{
${ }^{26}$ Even under voluntary demand, Cawley and Philipson (1996) present evidence that supports that selection on the demand side does not occur on private information about mortality in life-insurance markets.

${ }^{27}$ More precisely, we used a linear spline approximation $h(t \mid Y)$ to compute the yearly hazards using the reported hazard rates in 5 year intervals, and then compute the discrete time survival function according to $S(t \mid Y)=\prod_{s=0}^{t}(1-h(s \mid Y))$.
} 
Figure 3 below plots the size of the incentive component for different increases in the quantity. The three curves corresponds to three separate quantity increases from $Y_{L}=\$ 500$ per month to $Y_{H}=\$ 1250, \$ 1750$, and $\$ 2500$ per month. The figure reports the first incentive component using the annuity dependent survival functions of Figure 2.

A given curve corresponds to a given pair $\left(Y_{L}, Y_{H}\right)$ before and after the quantity increase, and each curve is plotted against the $\mathrm{x}$-axis representing the age at which the annuity starts. For example, the top curve indicates that if an annuity starts at age 70 then the incentive component in raising the quantity from $\$ 500$ to $\$ 2500$ per month is about 18 percent. In other words, of the increase in the annuity value that occurs when increasing the quantity, 18 percent is attributable to the increase in longevity due to the larger annuity. The feedback effects illustrated by the non-trivial incentive effects in these aggregate data suggest that a more careful empirical examination of the relationship between life-extension and public annuity expenditures may be warranted.

\section{Conclusion}

We analyze the savings and health care impact of mortality contingent claims, under which income earned is contingent on one's length of life. We stress the incentive effects of such mortality contingent claims on resources devoted to extend life. We discuss the effects that such claims have on savings and resources devoted to life-extension and argue, among other things, that life-extension is excessive under mandatory annuity programs such as Social Security; that public savings may increase private savings; that there may be an annuity-based gender bias in medical care; and that the lack of insurance of wives against the deaths of their husbands may have an efficiency basis. We further discussed the non-linear pricing of mortality contingent claims, the efficiency gains of not indexing annuities, and the important interactions between public subsidies for health and savings, interactions which are absent in models with exogenous mortality. Overall, we argue that the insurance aspects of mortality contingent claims have been overemphasized, relative to their incentives for resources devoted to life-extension through medical care. 
Our arguments may imply important differences with the standard theory of Ricardian equivalence. It is claimed there that inter-generational transfers have no real effects if children are altruistic towards parents or parents towards children. This is not necessarily true under endogenous mortality. If parents support children because they are altruistic, they have no artificial incentive to extend their lives. But if children support parents, our arguments show that there may be excessive investment in health. Moreover, if income is redistributed from parents to children, Ricardian equivalence says this has no effect, regardless of which one is altruistic. But if children are altruistic, such a redistribution will raise the incentive to invest in life-extension by parents.

Finally, although our discussion concerned the impact of annuities on mortality, this may not be the only channel through which annuities affect age distributions. If children and annuities are substitutes for old age income and health support, then mandatory annuities naturally lower the demand for children so that annuities may not only have effects on mortality but also on fertility. The overall impact of mandatory public annuity programs on the more recent part of the demographic transition, namely the postwar reductions in both mortality and fertility rates, therefore remains an important area of future research. 


\section{References}

[1] Arthur, W. (1981). 'The Economics of Risks to Life,' American Economic Review, v. 71, 54-64.

[2] Cagan, P. (1965). The Effects of Pension Plans on Aggregate Savings, New York: National Bureau of Economic Research.

[3] Cawley, J. and T. Philipson, (1996), 'An Empirical Examination of Information Barriers in Markets for Mortality Contingent Claims,' NBER Working Paper, Number 5669.

[4] Cox, D., (1987), 'Motives for Private Income Transfers,' Journal of Political Economy, 95, 3, 509-46.

[5] Ehrlich, I., and H., Chuma, (1990), 'A Model of The Demand for Longevity and the Value of Life Extension,' Journal of Political Economy, v. 98, 761-782.

[6] Green, F., (1981), 'The Effect of Occupational Pension Schemes on Savings in United Kingdom: A Test of The Life-Cycle Hypothesis', Economic Journal, v 91, 136-44.

[7] Grossman, M. (1972), 'On the Concept of Health Capital and The Demand for Health,' Journal of Political Economy, , v. 80, 223-50

[8] Hurd, M., (1990), 'Research on The Elderly: Economic Status, Retirement, and Consumption and Saving', Journal of economic Literature, $\mathrm{v}$ $28,2,565-637$.

[9] Katona, G., (1965), Private Pensions and Individual Savings, Ann Arbor: University of Michigan Press.

[10] King, M., and L., Dicks-Mireaux, (1982), 'Asset Holdings and The LifeCycle', Economic Journal, 247-267.

[11] Kotlikoff, L., (1989), What Determines Savings?, Cambridge: MIT Press.

[12] Posner, R. A., (1995), Aging and Old Age, Chicago and London: University of Chicago Press. 
[13] Poterba, J., S., Venti, and D., Wise, (1996), 'Do Retirement Savings Programs Increase Saving ?', forthcoming, Journal of Economic Perspectives.

[14] Rosen, S. , (1988), 'The Value of Changes in Life Expectancy,' Journal of Risk and Uncertainty, 1, 285-304.

[15] Rosen, S. (1994), 'The Quantity and Quality of Life: A Conceptual Framework' in Kenkel, D., G. Tolley, and R. Fabian, (Eds.), Valuing Health for Policy: An Economic Approach, Chicago: University of Chicago Press.

[16] Schoeni, R., and K., McGarry, (1995), 'Transfer Behavior in The Health and Retirement Study: Measurement and The Redistribution of Resources within The Family,' Journal of Human Resources, v. 30, S184S226.

[17] Taylor, A., and J., Banthin, (1994), Changes in Out-of- Pocket Expenditures for Personal health Services: 1977 and 1987, (AHCPR Pub. No., 94-0065), National Medical Expenditure Research Findings 21, Agency for Health Care and Policy Research, Rockville, MD; Public Health Service.

[18] Tengs, T., M., Damas, J., Pliskin, D. Safran, J., Siegel, M., Weinstein, and J. Graham, (1995), 'Five-Hundred Life-Saving Interventions and Their Cost-Effectiveness,' Risk Analysis, v. 15, 3, 369-390.

[19] World Bank, (1993), Investing in Health, World Bank Development Report, Oxford University Press.

[20] Yaari, M., (1965), 'Uncertain Life Time, Life-Insurance, and The Theory of The Consumer,' Review of Economic Studies, v. 32, 137-50.

[21] Virga, M., (1996), 'Earn More, Live Longer-Variation in Mortality by Income Level', Society of Actuaries, March 1996. 
Life Length

(T)

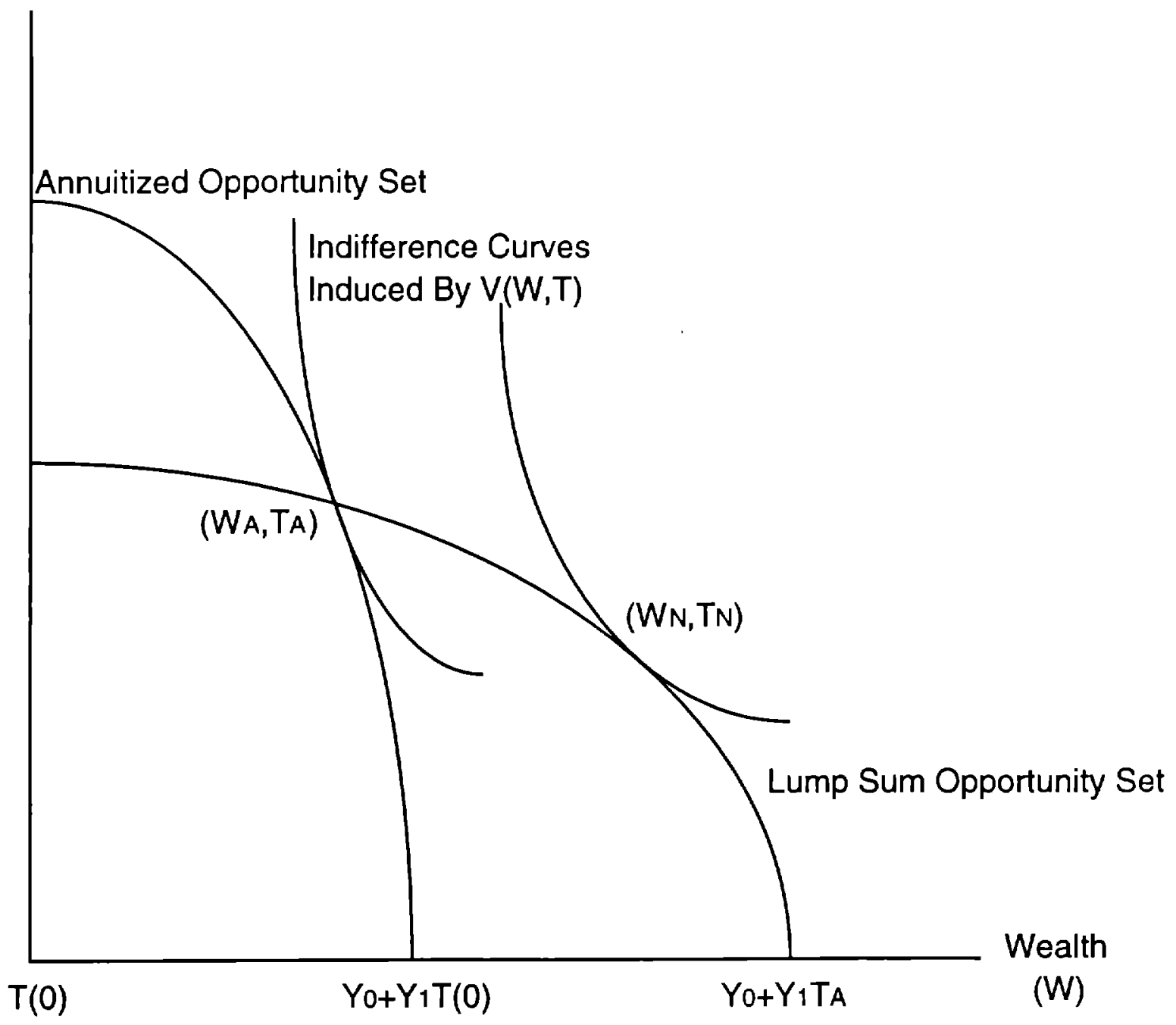

Figure 1: Life Extension and Annuitization 


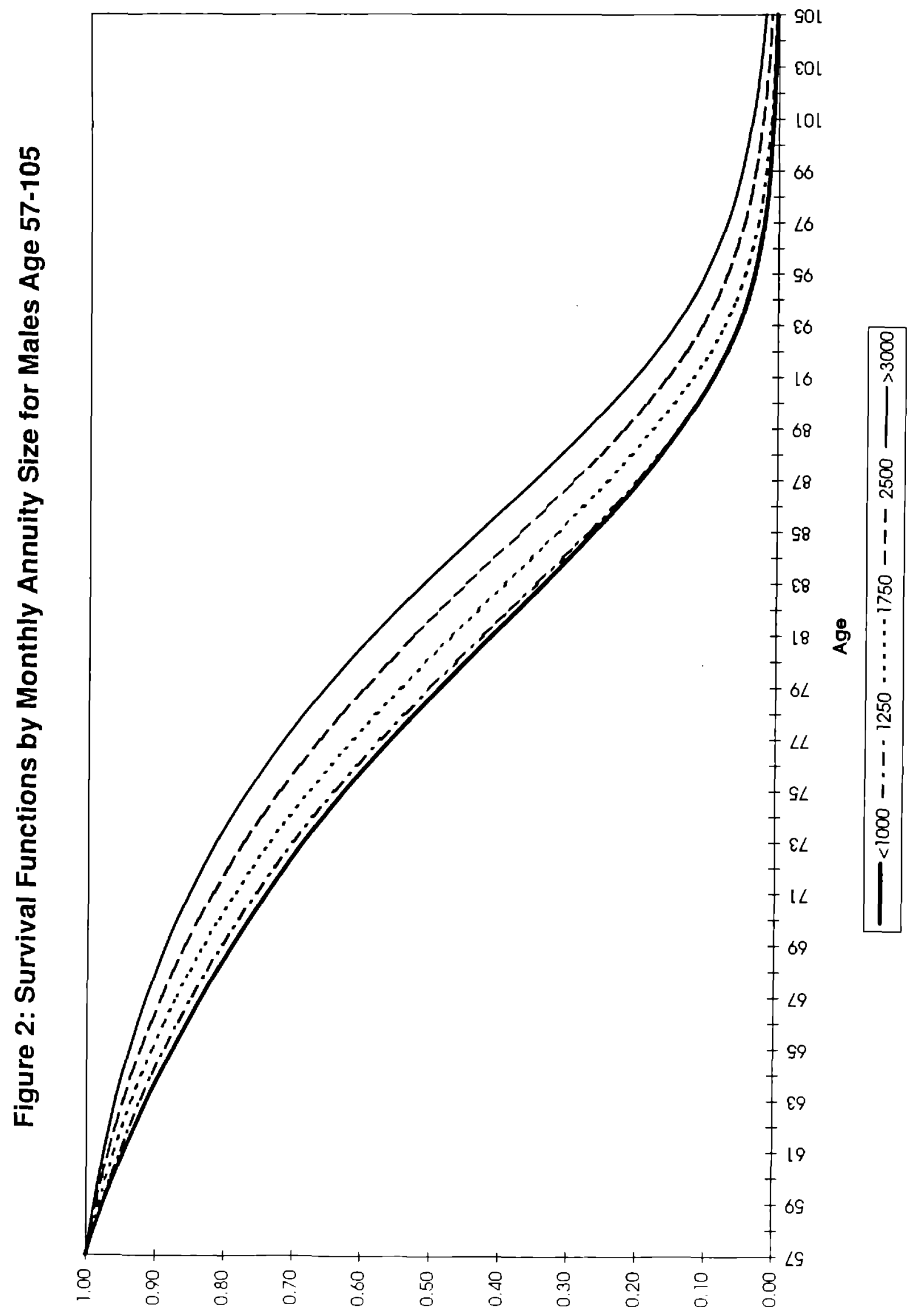




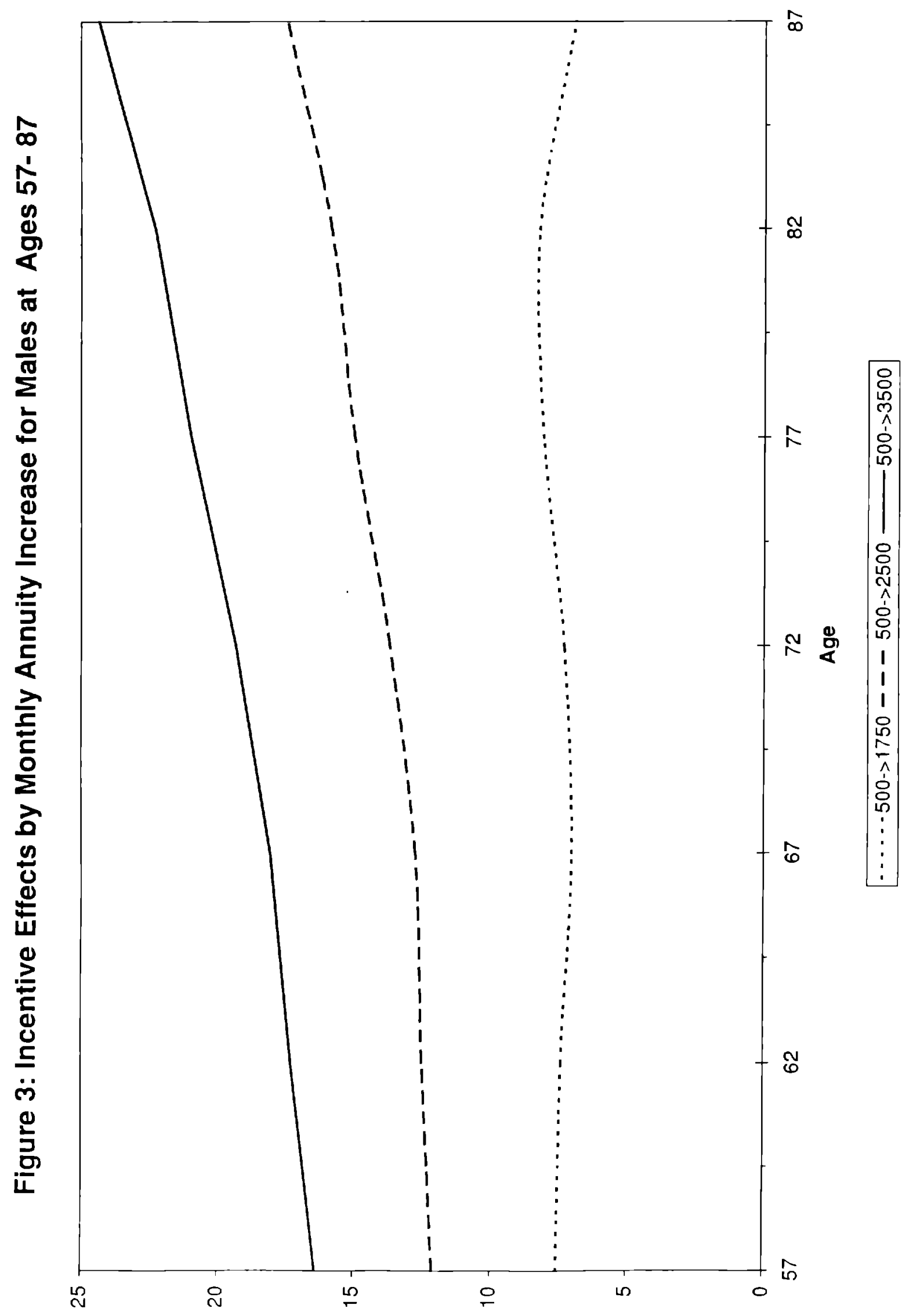

